\title{
Analysis of patient load data from the 2003 Cricket World Cup in South Africa
}

\author{
A Kilian ${ }^{1}$ (MB ChB) \\ R A Stretch ${ }^{2}$ (D Phil) \\ ${ }^{1}$ Medical doctor in private practice, Port Elizabeth \\ ${ }^{2}$ Sport Bureau, Nelson Mandela Metropolitan University, Port Elizabeth
}

\begin{abstract}
Objectives. The purpose of this study was to evaluate the patient presentation data for spectators attending the opening ceremony and all the 2003 Cricket World Cup matches played in South Africa in order to provide organisers with the basis of a sound medical care plan for mass gatherings of a similar nature.
\end{abstract}

Methods. During the 2003 Cricket World Cup, data were collected on the spectators presenting to the medical facilities during the opening ceremony and the 42 matches played in South Africa. Data included the total number of patient presentations and the category of illness or injury. This information was used to determine the venue accommodation rate and the patient presentation rate. The illness/injury data were classified into the following categories: (i) heat-related illness; (ii) blisters/scrapes/ bruises; (iii) headache; (iv) fractures/sprains/lacerations; (v) eye injuries; (vi) abdominal pain; (vii) insect bite; (viii) allergy-related illness; (ix) cardiac disorders, chest pains; $(x)$ pulmonary disorder/shortness of breath; (xi) syncope; (xii) weakness/dizziness; (xiii) alcohol/drug-related conditions; (xiv) seizure; (xv) cardiac arrest; (xvi) obstetric/ gynaecological disorder; and (xvii) other.

Results. The total number of patients who presented to the medical stations was 2118 , with a mean of 50 (range 14 - 91) injuries per match. The mean for the patient presentation rate was $4 / 1000$ spectators. The most frequently encountered illness or injury was headache (954 patients, $45 \%$ ), followed by fractures, sprains and lacerations (351 patients, $16 \%$ ).

\section{CORRESPONDENCE:}

\section{R Stretch}

\section{Sport Bureau}

Nelson Mandela Metropolitan University

PO Box 77000

Port Elizabeth

6031

Tel: 041-504 2584

Fax: 041-583 2605

E-mail: Richard.Stretch@nmmu.ac.za
Conclusion. The unique nature of cricket has shown a different patient presentation rate than for other similar mass gatherings, requiring additional factors be considered when developing a medical care plan.

\section{Introduction}

In addition to the medical support that is offered to an international team, medical coverage for spectators also needs to be provided at large sporting events. This has been highlighted by a number of incidents at soccer matches in particular. In 1992, 17 people were killed and 1900 injured when a temporary stand collapsed in Corsica. In the same year 43 and 126 people were killed as a result of spectators attempting to push their way into a soccer stadium in South Africa and Ghana, respectively. ${ }^{1}$

Further, the terrorist attack at the 1996 Olympic Games in Atlanta where 111 people were injured ${ }^{1}$ and the terrorist attacks in the USA on 11 September 2001 and in London in 2005 , have made event organisers aware of the need for preparedness planning for large sporting events.

Medical coverage for the needs of spectators at large sporting events should cater for situations where medical personnel are able to deal with one case at a time, to events with isolated major incidents or in extreme cases such as a mass casualty or disaster situation.

In preparation for the 2002 FIFA World Cup in Japan, the Health Research Team (HRT-MHLW) was established by the Japanese government to provide an effective service for spectators attending the matches played in Japan, as well as to analyse factors regarding patient presentations with a view to develop a medical care plan for mass gatherings. ${ }^{3} \mathrm{~A}$ total of 1661 patients presented with illness or injuries to the medical stations during the 32 matches played in Japan. This patient presentation rate was $1.21 / 1000$ spectators, with a transport-to-hospital rate of $0.05 / 1000$ spectators. As the total number of spectators increased, the patient presentation rate decreased, while the patient presentation rates increased when spectators were not provided with shuttle-bus transport from the nearest railway station or had to walk for more than 12 minutes to gain access to the venue.

While injuries to cricket players in South Africa, ${ }^{6-12}$ Australia $^{5}$ and England ${ }^{4}$ have been well documented over 
the past number of years, there have not been any reported studies on the illness/injury rate of spectators attending major cricket matches or events. The purpose of this study was to evaluate the patient presentation data for spectators attending the opening ceremony and all the 2003 Cricket World Cup matches played in South Africa and to compare these with similar findings from the 2002 FIFA World Cup held in Japan, in order to provide organisers with a basis for a sound medical care plan for mass gatherings of a similar nature.

\section{Method}

The 2003 Cricket World Cup was organised in February and March 2003, with the opening ceremony staged in South Africa and 54 matches staged in South Africa, Zimbabwe and Kenya. Only the opening ceremony and the 42 matches played in South Africa formed part of this study. The opening ceremony was held in the evening, with the one-day international matches played either as day matches (10h00 to about $17 \mathrm{~h} 30$ ) or as day-night matches (14h30 to about 22h00).

All the planning and procedures relating to the medical management of the spectators and players for all matches were the responsibility of the medical committee. Only the spectator data are presented in this study. The medical committee held monthly meeting from January 2002 to May 2003 (16 meetings) and three seminars with the medical personnel prior to the start of the competition. Based on this a medical system was put in place for each venue that would be able to respond to a disaster, as well as providing routine on-site medical emergencies.
To ensure adequate medical cover there was at least one medical station at each ground, staffed by 2 doctors, 2 nurses and on average 3 paramedics. The medical support was provided from 2 hours before the start of the match to 1 hour after the end of the match. The necessary medical supplies and equipment were available at each medical station. An ambulance was available at each venue to transfer patients to hospital if necessary. Further, at least one hospital in each city was put on stand-by in the event of an emergency, with the normal daily staff on stand-by.

The data collected included the total number of spectators at each match and the maximum spectator capacity for each venue. The medical personnel in charge of the medical facility documented patient information which included the total number of patient presentations (PP) and the category of illness/injury (I). These data were used to determine the venue accommodation rate (VAR). This was defined as the actual number of spectators per game compared with the maximum spectator capacity of the venue. The patient presentation rate (PPR) was defined as the number of patients per 1000 spectators per match.

To allow comparisons with similar data from the 2002 FIFA World $\mathrm{Cup}^{3}$ the illness/injury data were classified into the following: (i) heat-related illness; (ii) blisters/scrapes/ bruises; (iii) headache; (vi) fractures/sprains/lacerations; (v) eye injuries; (vi) abdominal pain; (vii) insect bite; (viii) allergy-related illness; (ix) cardiac disorders; chest pains; $(x)$ pulmonary disorder/shortness of breath; (xi) syncope; (xii) weakness/dizziness; (xiii) alcohol/drug-related conditions; (xiv) seizure; (xv) cardiac arrest; (xvi) obstetric/gynaecological disorder; and (xvii) other.

TABLE I. Spectator, venue and patient presentation data during the 2003 Cricket World Cup

\begin{tabular}{|c|c|c|c|c|c|c|c|c|}
\hline Venues & $\begin{array}{l}\text { Matches } \\
(N)\end{array}$ & $\begin{array}{l}\text { Maximum } \\
\text { spectator } \\
\text { capacity } \\
(N)\end{array}$ & $\begin{array}{c}\text { Mean venue } \\
\text { accommodation } \\
\text { rate } \\
(N)\end{array}$ & $\begin{array}{c}\% \text { of } \\
\text { capacity } \\
(\%)\end{array}$ & $\begin{array}{l}\text { Total spectator } \\
\text { attendance } \\
\text { (N) }\end{array}$ & $\begin{array}{c}\text { Patient } \\
\text { presentations } \\
(N)\end{array}$ & $\begin{array}{c}\text { Mean/match } \\
(N)\end{array}$ & $\begin{array}{c}\text { Presentations/ } \\
1000 \\
\text { spectators } \\
(N)\end{array}$ \\
\hline Paarl & 3 & 9030 & 4207 & 47 & 12620 & 57 & 19 & 4 \\
\hline Durban & 5 & 19980 & 16292 & 82 & 81459 & 215 & 43 & 2 \\
\hline Pietermaritzburg & 3 & 7091 & 3883 & 55 & 7765 & 42 & 21 & 5 \\
\hline Potchefstroom & 2 & 10169 & 5902 & 58 & 17706 & 44 & 14 & 2 \\
\hline Pretoria & 4 & 21160 & 15427 & 72 & 61706 & 366 & 91 & 5 \\
\hline Johannesburg & 5 & 30542 & 26235 & 86 & 131175 & 427 & 85 & 3 \\
\hline Kimberley & 2 & 6056 & 3328 & 55 & 6655 & 48 & 24 & 7 \\
\hline Port Elizabeth & 5 & 18109 & 12206 & 67 & 61031 & 241 & 48 & 3 \\
\hline Cape Town* & 6 & 23141 & 20170 & 87 & 121020 & 508 & 85 & 4 \\
\hline East London & 2 & 13248 & 5610 & 42 & 11220 & 36 & 18 & 3 \\
\hline Benoni & 2 & 9812 & 4719 & 48 & 9437 & 49 & 25 & 5 \\
\hline Bloemfontein & 3 & 13954 & 4792 & 34 & 14377 & 85 & 28 & 5 \\
\hline Total & 42 & 738508 & 536171 & - & 536171 & 2118 & - & - \\
\hline
\end{tabular}




\section{Results}

There were 12 venues used to stage the 42 World Cup matches, with an average of 4 (range 2 - 6) matches per venue. The mean maximum venue capacity was 17583 (range 6056 - 30 542) spectators, with a total capacity of 738508 spectators for the venues for all 42 matches. The total attendance at all 42 matches was 536171 spectators, with a mean actual attendance of 12765 (range 3328 - 26 235) or $73 \%$ (range $34-87 \%$ ) of the total capacity for all the venues (Table I).

The total number of patients who presented to the medical stations was 2118 , with a mean of 50 (range 14 - 91) injuries or illnesses per match. The mean patient presentation rate was $4 / 1000$ spectators, with the matches played in Potchefstroom and Durban (3/1 000 spectators) and at Kimberley (71/1 000 spectators) reporting the lowest and highest rates, respectively (Table I).

The most frequently encountered illness or injury was headache (954 patients, 45\%), followed by fractures, sprains and lacerations (351 patients, 16\%) (Table II). Other presentations included allergy-related illnesses (129 patients, $6 \%$ ), abdominal pain (120 patients, $6 \%$ ) and heatrelated illnesses (103 patients, 5\%). The 'Other' category of illnesses or injuries (322 patients, 15\%) included 88 (4\%) patients with gastric problems and $48(2 \%)$ and $19(1 \%)$ with urinary tract and respiratory tract infections, respectively.

\section{Discussion}

The unique nature of cricket, which is played over an extended period of time, has shown a different patient presentation rate than that of soccer.3 Firstly, the cricket spectators showed a greater patient presentation rate per 1000 spectators, although it still falls within the range of 0.14 - 90 patients per 1000 spectators. ${ }^{2}$

A number of factors may influence the patient presentation rate, with venue capacity and the crowd size being identified as the more important factors. ${ }^{13}$ The crowd density is indicated by the venue accommodation rate. However, neither of these variables were factors in the patient presentation rate. The matches played at Kimberley, the venue with the lowest mean venue accommodation rate, had the highest rate of injuries per 1000 spectators. Conversely, Johannesburg, the venue with the greatest mean venue accommodation rate, had one of the lower rates of injuries per 1000 spectators. This may possibly be due to the fact that a number of other factors such as weather conditions and location of seating may play a more significant role in the risk illness or injury to spectators at cricket matches.

A second difference was that more than half of the patients at cricket matches presented with headaches and heat-related illnesses, while at soccer matches ${ }^{3}$ this only made up about $15 \%$ of the recorded injuries/illnesses. Again
TABLE II. Category of medical condition and the number $(N)$ of patient presentations at the 2003 Cricket World Cup

\begin{tabular}{lrc}
\hline & $\begin{array}{c}\text { Patient } \\
(\boldsymbol{N})\end{array}$ & $\begin{array}{c}\text { Presentations } \\
(\%)\end{array}$ \\
\hline Blisters, scrapes and bruises & 23 & 1 \\
Headache & 954 & 45 \\
Abdominal pain & 120 & 6 \\
Heat-related illnesses & 103 & 5 \\
Fracture, sprain and lacerations & 351 & 16 \\
Weakness/dizziness & 6 & 1 \\
Cardiovascular disorders/chest pains & 16 & 1 \\
Insect bites & 25 & 1 \\
Pulmonary disorders/shortness of breath & 19 & 1 \\
Alergy-related & 129 & 6 \\
Eye injury & 40 & 2 \\
Other & 322 & 15 \\
Total & 2118 & 100 \\
\hline
\end{tabular}

this may be related to other factors, some of which may be beyond the control of the event organisers.

During the 2002 Soccer World Cup temperature had an effect on the number of injuries, with an increase in temperature associated with an increased risk of illness or injury, particularly heat-related illnesses, headaches and weakness or dizziness. ${ }^{3}$ One of the limitations of the study was that no information was obtained on the weather conditions. Although the effect of heat on the risk of illnesses or injury could not be determined, the 2003 Cricket World Cup was played in the hot summer months of February and March.

In conclusion, the basic epidemiological data collected at the 2003 Cricket World Cup should assist organisers of future Cricket World Cup competitions to predict patient presentation rates. However, the unique nature of cricket requires additional factors that need to be considered when collecting similar data. This should include weather conditions, time of day or night when the patient presented, and information on whether the patient was seated in undercover seating or on the open grass banks that are common at many cricket grounds. This could then assist in developing a medical care plan in accordance with the capacity of the venue in order to provide the most efficient medical care possible.

\section{REFERENCES}

1. Delaney JS, Drummond R. Mass casualties and triage at a sporting event Br J Sports Med 2002; 36: 85-8.

2. De Lorenzo RA. Mass gathering medicine: A Review. Prehosp Disast Med 1997; 12: 68-72.

3. Morimura N, Katsumi A, Koido Y, et al. Analysis of patient load data from the 2002 FIFA World Cup Korea/Japan, Prehosp Disast Med 2004; 19: 278 - 4. 


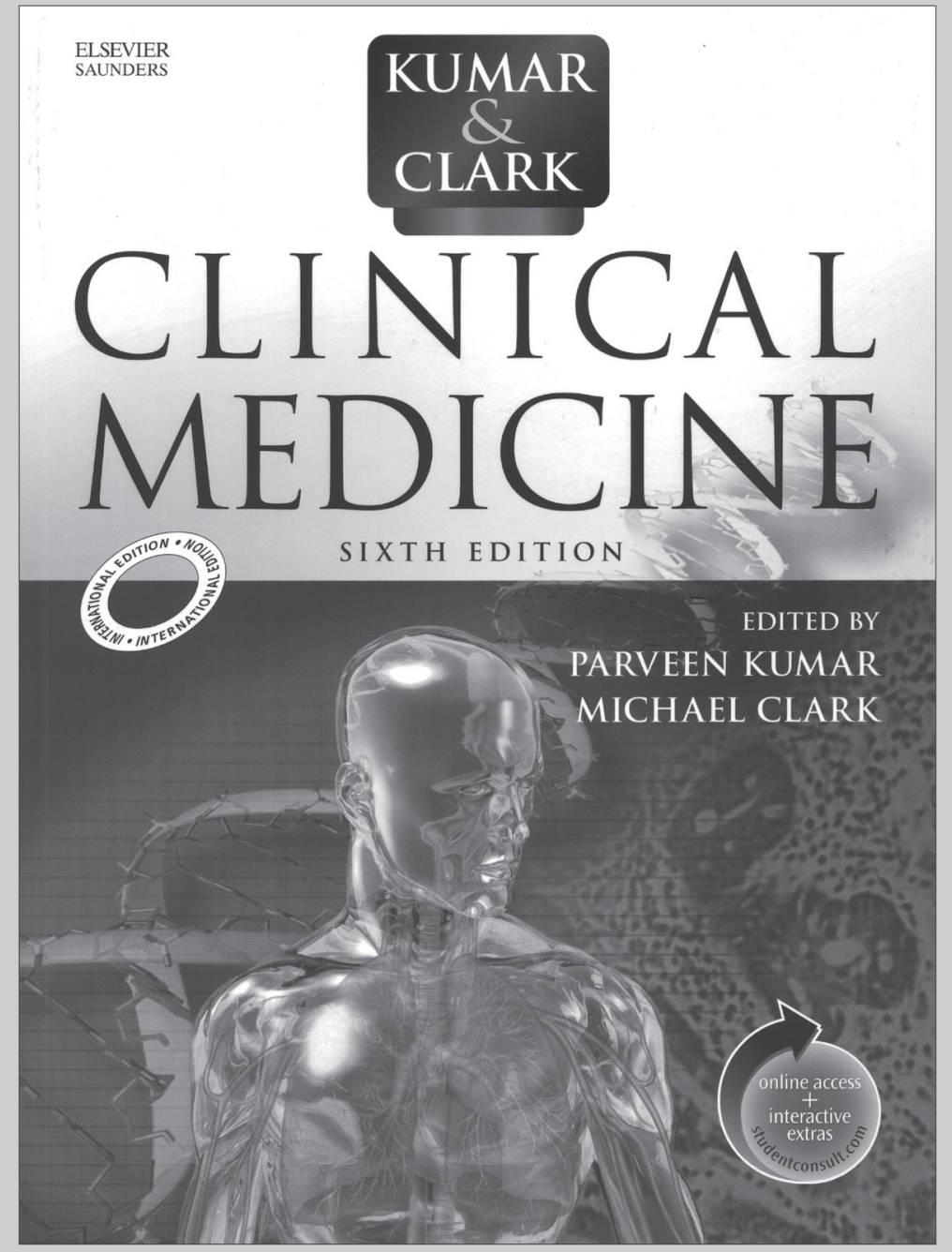

\section{PRICE: R380.00}

\section{SAMA MEMBERS: R360.00}

\section{TO ORDER CONTACT:-}

South African Medical Association

Health \& Medical Publishing Group

1-2 Lonsdale Building, Gardener Way,

Pinelands, 7405

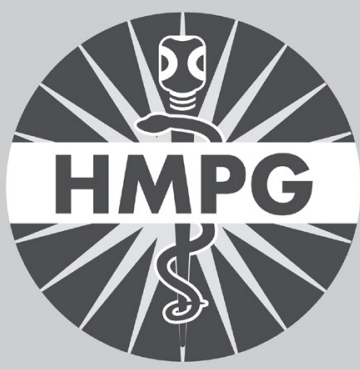

$$
\text { Tel: (021) 530-6520/27 }
$$

Fax: (021) 531-4126/3539

email: carmena@hmpg.co.za

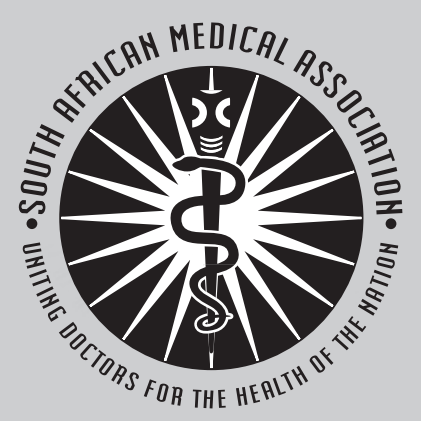


4. Newman DA. Prospective survey of injuries at first class counties in England and Wales 2001 and 2002 seasons. In: Stretch RA, Noakes, TD, Vaughan CL, eds. Science and Medicine in Cricket Compress: Cape Town, 2003; 343-50.

5. Orchard J, James T, Alcott E, Carter S, Farhart P. Injuries in Australian cricket at first class level 1995/1996 to 2000/2001. Br J Sports Med 2002; 36: $270-5$.

6. Stretch RA. Injuries to South African cricketers playing at first-class level. S Afr Med J 1989; 4: 3-20.

7. Stretch RA. The incidence and nature of injuries in club and provincia cricketers. South African Medical Journal 1993; 83: 339-41.

8. Stretch RA. The incidence and nature of injuries in schoolboy cricketers. $S$ Afr Med J 1995; 85: 1182-4.
9. Stretch RA. Incidence and nature of epidemiological injuries to elite South African cricket players. S Afr Med J 2001a; 91:336-9.

10. Stretch RA. The incidence and nature of epidemiological injuries to elite South African cricket players over a two-season period, South African Medical Journal 2001b; 8:17 - 20.

11. Stretch RA. Cricket injuries: a longitudinal study of the nature of injuries to South African cricketers. Br J Sports Med 2003; 37: 250 - 3.

12. Stretch RA, Venter DJL. Cricket injuries: A longitudinal study of the nature of injuries to South African cricketers. South African Medical Journal 2003; 15: 4 - 8 .

13. Zeitz KM, Schneider DP, Jarrett D. Mass gathering events: Retrospective analysis of patient presentations over seven years. Prehosp Disast Med 2002; 17: 147-50.
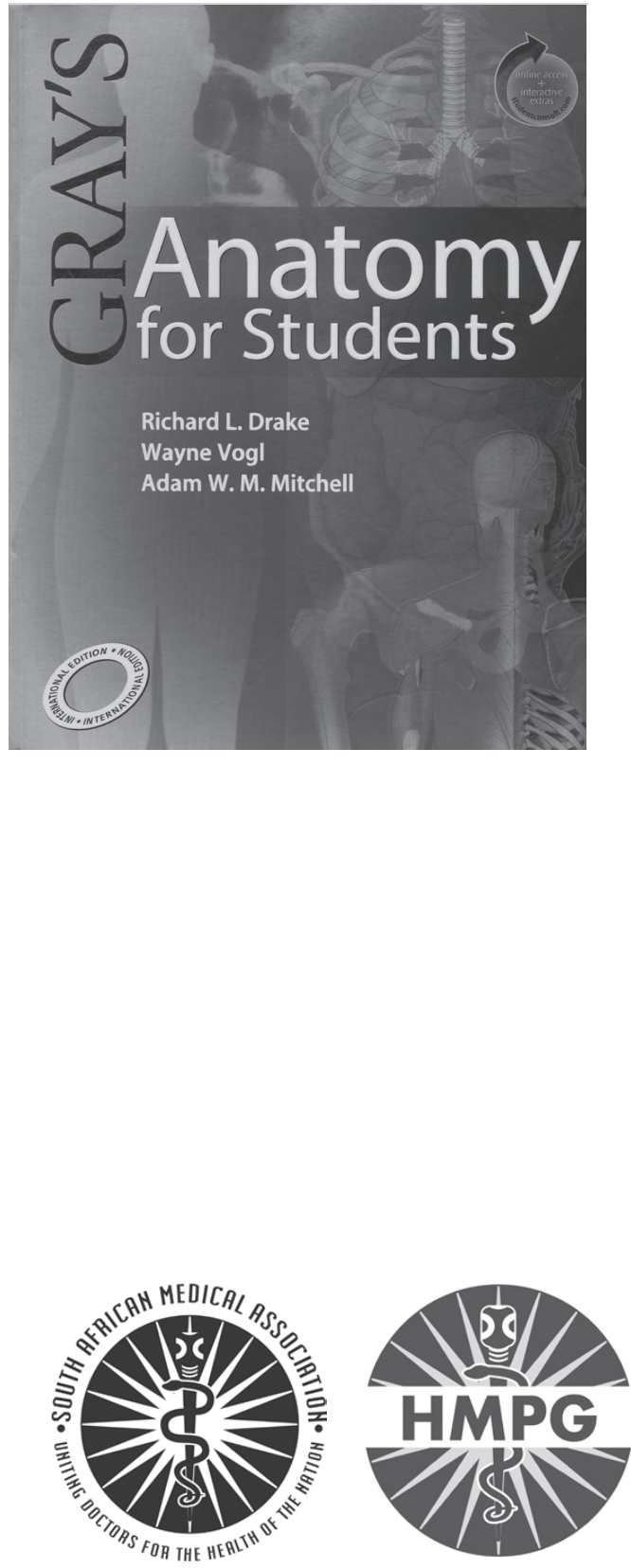

\section{PRICE: R399.00}

To order contact Carmen or Avril:

Tel: (021) 530-6520

Fax: (021) 531-4126/3539

email: carmena@hmpg.co.za

The South African Medical Association, Health \& Medical Publishing Group 1-2 Lonsdale Building, Gardener Way, Pinelands, 7405. 